\title{
A Novel Formulation Approach for Preparation of Nanoparticulate Red Mold Rice
}

\author{
Chiun-Chieh Yu, Chun-Lin Lee, and Tzu-Ming Pan*
}

Institute of Microbiology and Biochemistry, National Taiwan University, 1, Section 4, Roosevelt Road, Taipei, Taiwan, Republic of China

\begin{abstract}
Monascus has been used for thousands of years. In China, Monascus has been widely used as a natural food-coloring agent for many kinds of foods. The metabolites of Monascus species, specifically, monacolin $\mathrm{K}, \gamma$-aminobutyric acid, and dimerumic acid, have been proven to have cholesterol-lowering, blood pressure-lowering, and antioxidant effects. Nowadays, the public has recognized the importance of Monascus products for its many health benefits. The focus of this study is to explore the effects of nanoparticulate dispersion of red mold rice (RMR) after wet-milling technology treatment. An RMR nanoparticulate formulation was reproducibly obtained after milling in the presence of dispersing agent and water. Furthermore, the physical and chemical properties of these RMR particles were studied using electron microscopy, laser light scattering, $\mathrm{pH}$ meter, high-performance liquid chromatography (HPLC), and photometry. The results demonstrate that RMR (mean size $=20.15 \mu \mathrm{m})$, processed with wet-milling technology, forms an aqueous-based nanoparticle dispersion (mean particle size of less than $0.41 \mu \mathrm{m}$ ). In addition, HPLC analyses, performed on the secondary metabolites, demonstrated that monacolin $\mathrm{K}$ was reduced to $50-92 \%$ of its base level and citrinin was reduced to $48-74 \%$ of its base level. When testing for the levels of $\mathrm{pH}$, the processed RMR had increased from a pH level of $4.47-4.82$ to $5.56-6.4$; also, pigment analysis showed that yellow and red pigments were reduced to 36 and $39 \%$ of its base level after the wet-milling process. Partial agglomeration has been observed in RMR dispersion when stored in refrigeration after 2 months. RMR can be formulated as a nanoparticulate dispersion without compromising its stability, but its secondary metabolite extraction rate was changed. Further experimentation will be needed to verify safety and functionality evaluations.
\end{abstract}

\section{KEYWORDS: Monascu; nanoparticulate; monacolin K; citrinin}

\section{INTRODUCTION}

Monascus, a traditional Chinese fermentation fungi, has been used in many kinds of foods for thousands of years $(1,2)$. It is generally recognized for its health benefits because of the proven benefits of the secondary metabolites such as the monacolins $(3-5), \gamma$-aminobutyric acid (GABA), and dimerumic acid. One of the well-documented metabolites of Monascus is monacolin $\mathrm{K}$, which has been identified for its cholesterol-lowering properties due to the competitive inhibitory effect on HMG-Co A reductase (4). In addition, the blood pressure-lowering effects of $\operatorname{GABA}(6,7)$ and the antioxidant effects of dimerumic acid (8) are also well-known. Although Monascus is capable of producing these bioactive compounds, there is a possibility of synthesizing citrinin, a hepatonephrotoxic mycotoxin, during fermentation (9). Red mold rice (RMR), the common fermented product of Monascus, has been recommended as a dietary supplement $(5,10)$. As a healthy type food, the need to improve the absorption of monacolin $\mathrm{K}$ and reduce the effects of toxicity

* To whom correspondence should be addressed. Tel: +886-2-33664519. Fax: +886-2-23627044. E-mail: tmpan@ntu.edu.tw. remains a key point for commercial development. Many approaches have been introduced and even applied for solving such problems; in fact, the application of nanotechnology, which reduces the particle size to nanometer scale, may be useful in this field (11). The unique characteristics of nanoparticles are their particle size effects and high surface reactivity, which offer broad applications in medicines and biomaterials (12). Pharmaceutically, the nanoparticles have been researched and developed for drug delivering, nanocoating, carrier, and numerous other applications $(13,14)$. Using wet media-milling technology, a nanoparticle preparation of zinc-insulin was formulated and successfully improved the water solubility and bioavailability (15). However, there are few studies aimed at discussing the nanopaticulate process and its effects on biomaterials, especially in foods. In this study, we describe a physically stable nanoparticulate formulation of RMR processed by a high-energy wet-milling method. The nanoparticulate red mold rice (NRMR) dispersion appears to have different physical and chemical properties that can be measured by using electron microscopy, laser light scattering, $\mathrm{pH}$ meter, high-performance liquid chromatography (HPLC), and photometry. 


\section{MATERIALS AND METHODS}

Materials. RMR used in this study was obtained from a local traditional market in Taipei. The species of the rice used in this study was indica rice (Oryza sativa L. spp. indica). Yttria-stabilized zirconia grinding media were purchased from Toray Industries, Inc. (Chuo-ku, Tokyo, Japan). Monacolin K, citrinin, and sodium deoxycholate were purchased from Sigma-Aldrich Fine Chemicals (St. Louis, MO). Arabic gum TCML and arabic gum no. 408 were purchased from Taiwan Gum Arabic Co. (Chung-Ho, Taipei county, Taiwan). The pluronic stabilizer F68 was purchased from BASF Pharma Solutions (Ludwigshafen, Germany). Dimethyl sulfoxide was purchased from Wako Pure Chemicals (Osaka, Japan).

Formulation of NRMR Dispersion. A NRMR formulation was prepared using a wet-milling process and different dispersing agents to provide efficient particle size reduction and maximum stability. In the end, a physically stable NRMR product was produced. NRMR dispersions were prepared as follows: Crude RMR was ground into flour by utilizing a two-step process. The proper amount of RMR (10 g) was added into a bean grinder and ground for $30 \mathrm{~s}$. Powder collected from the first step $(30 \mathrm{~g})$ was ground again using a cyclone sample mill until no obvious solid particles could be observed. Dried RMR powder was weighted $(20 \mathrm{~g})$ and stirred gently for $30 \mathrm{~min}$ with aqueous solutions $(200 \mathrm{~mL})$ of arabic gums, $0.5 \%$ F68/0.05\% sodium deoxycholate, $0.1 \% \mathrm{~F} 68 / 0.01 \%$ sodium deoxycholate, and distilled water, respectively. The crude RMR slurry was added to a roller mill jar containing zirconia grinding media $(600 \mathrm{~g})$ and placed on the mill NM0010 (Fu Chun Shin Co., Tainan, Taiwan). The wet-milling process was achieved by using $0.65 \mathrm{~mm}$ grinding media for $1 \mathrm{~h}$ and $0.2 \mathrm{~mm}$ grinding media for another $3 \mathrm{~h}$. Processing was performed at $3000 \mathrm{rpm}$, and the power output of the mill was $80 \mathrm{~W}$. The NRMR dispersion was collected for particle size determination and secondary metabolite analysis. After they were processed, the dispersions were harvested and used for the studies described below.

Particle Size Determination. The particle size was estimated by dynamic laser scattering and electron microscopy. Dynamic light scattering measurements were performed using the Zetasizer-3000HS (Malvern Instruments, Worcestershire, United Kingdom) for studying sizes and shapes of nanoparticulates in liquids (16). Prior to use, the instrument was calibrated using standard microspheres $(0.199 \pm 0.006$ $\mu \mathrm{m})$ and samples were assayed after being diluted with deionized distilled water, filtered with $3 \mu \mathrm{m}$ filter paper, and then ultrasonicated for $20 \mathrm{~min}$. Light scattering measurements were verified using electron microscopy. For transmission electron microscope (TEM) analysis, a diluted sample was visualized using a Hitachi H-7100 (Hitachi Co., Tokyo, Japan). For scanning electron microscope (SEM) analysis, samples were diluted with deionized-distilled water and an aliquot was dried, sputter-coated, and visualized using the TOPCON ABT150S (Topcon Technologies Inc., Pleasanton, CA). In particle size analysis, there was insufficient evidence to estimate average sizes of RMR and NRMR particles by SEM or TEM images. The mean particle sizes can be estimated by dynamic laser scattering measurement (16).

HPLC Analysis. For chemical stability analysis, the secondary metabolite of the NRMR formulations was assayed using a modification of previously described methods. The NRMR dispersion was freezedried, and $1 \mathrm{~g}$ of dried NRMR samples was extracted with $10 \mathrm{~mL}$ of ethanol at $65^{\circ} \mathrm{C}$ for $1.5 \mathrm{~h}(17)$. The extracts (10\% w/v) were further filtered with $0.45 \mu \mathrm{m}$ filter and analyzed by HPLC. HPLC was performed according to the method described previously (18) and carried out on an HPLC system PU2089 plus (Jasco Co., Tokyo, Japan). A Discovery C18 column, $25 \mathrm{~cm} \times 4.6 \mathrm{~mm}$ i.d., $5 \mu \mathrm{m}$ (Bellefonte, PA), was used as the analytical column. The mobile phase was formed using $45 \%$ water, $55 \%$ acetonitrile, and $0.5 \%$ triflouacetate at a flow rate of $1.0 \mathrm{~mL} / \mathrm{min}$. Monacolin $\mathrm{K}$ was detected using a UV detector UV2075 plus (Jasco Co.) set at $238 \mathrm{~nm}$. For citrinin analysis, the fluorescence detector FL-1 (Rainin Co, Wobum, MA) was set with an excitation $\lambda_{\max }$ of $330 \mathrm{~nm}$ and an emission $\lambda_{\max }$ of $500 \mathrm{~nm}$.

General Analysis. The $\mathrm{pH}$ value of RMR was acidic because of production of organic acid (19) by the Monascus species. The NRMR dispersion was assayed by pH meter model 6071 (Jenco Co., San Diego, CA) for determination of the $\mathrm{pH}$ value changes after the wet-milling

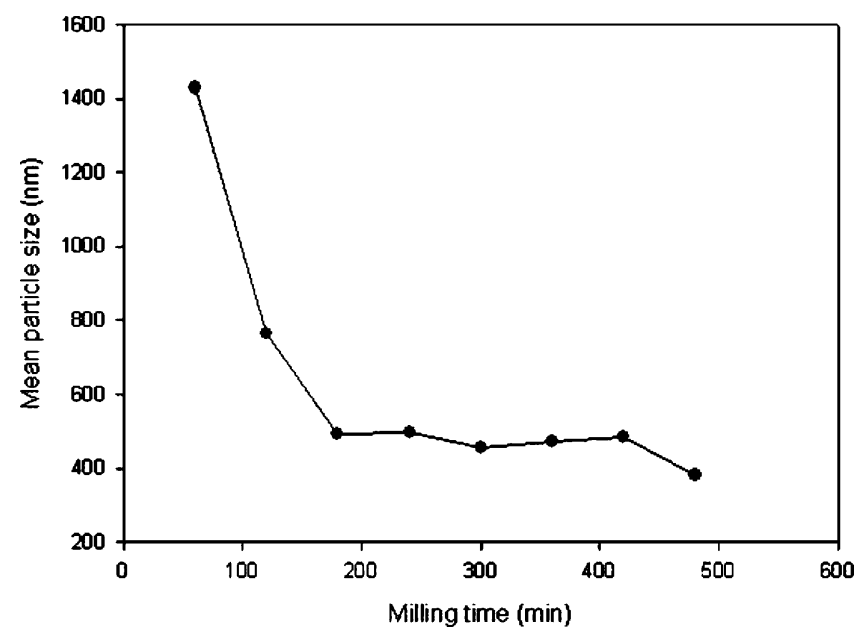

Figure 1. Particle size reduction/time curve for RMR dispersion processed using a high-energy wet milling technology for $8 \mathrm{~h}$.

process to see if the acid environment could be neutralized by the breakage of cell wall. The appearance of the aqueous-based NRMR was recorded during storage under $4{ }^{\circ} \mathrm{C}$ for 2 months. Red pigment and yellow pigment analyses of RMR were diluted and then measured by spectrophotometer U-2001 (Hitachi Instruments Inc.) at $\mathrm{OD}_{500}$ and $\mathrm{OD}_{400}$, respectively (20).

Food Composition Analysis. The food composition analysis of RMR was performed according to the standard procedures of AOAC to determine the water, ash, lipid, protein, and carbohydrate contents (21). The water content was determined by drying the RMR in a 105 ${ }^{\circ} \mathrm{C}$ oven to constant weight. To analyze the ash content, RMR was preheated $250{ }^{\circ} \mathrm{C}$ for $2 \mathrm{~h}$ and heated at $550{ }^{\circ} \mathrm{C}$ for $16 \mathrm{~h}$, and the ash content was calculated. The Soxhlet method was used for determination of the RMR lipid content. For protein content examination, RMR was treated with the Kjeldahl method to obtain the total nitrogen content and the nitrogen factor of rice (5.95) was used to calculate the crude protein content of RMR. Finally, the carbohydrate content of RMR was calculated by eliminating the total moisture, crude protein, crude lipid, and ash.

\section{RESULTS}

NRMRs were generated using wet-milling technology. As described in the Materials and Methods, $20 \mathrm{~g}$ of RMR powder with $200 \mathrm{~mL}$ of double-distilled water was mixed and then ballmilled without dispersive agents. The impaction and the shearing forces generated during milling were necessary in order to achieve the desired results. In Figure 1, the particle size reduction profile of the RMR powder is shown. The graph shows that within $3 \mathrm{~h}$ of processing, the mean particle size of the powder is reduced from $20 \mu \mathrm{m}$ to $500 \mathrm{~nm}$. Further processing yielded homogeneous particle preparation with a mean particle size of about $410 \mu \mathrm{m}$.

Using SEM, as shown in Figure 2, with $700 \times$ magnification, the larger unmilled RMR powder became smooth after $4 \mathrm{~h}$ of processing. Moreover, under $10000 \times$ magnification, the smooth surface area revealed the contours of NRMR structures. Using TEM, the homogeneity and the effectiveness of the wet-milling process were readily evident. As shown in Figure 3, with 4000× magnification, the milled NRMR is a highly dispersed nanoparticulate preparation. In addition, under $10000 \times$ magnification, nanoparticulates, which ranged from 300 to $500 \mathrm{~nm}$ in size, were clearly observed and demonstrated the ideal homogeneous and dispersive properties. SEM and TEM photos further support the particle size data from laser scattering measurement. After 1 week, unmilled RMR precipitated, but milled RMR still retained its dispersive condition (Figure 4). 
(A)

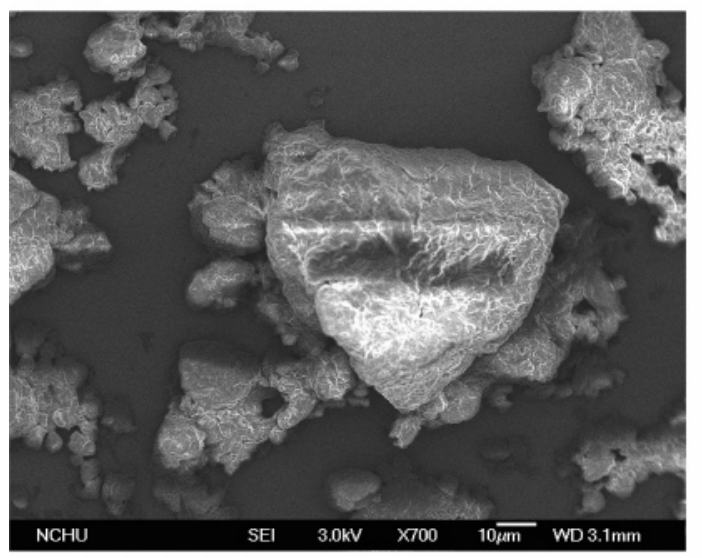

(B)

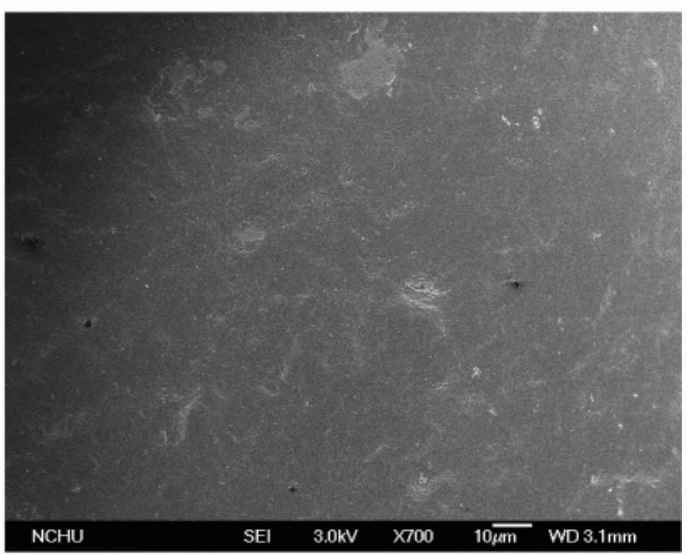

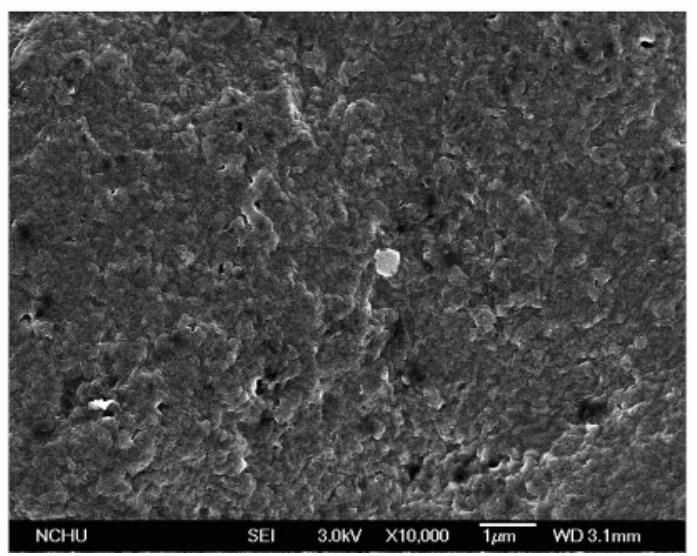

Figure 2. Micrographs compare (A) unmilled RMR powder and (B) milled RMR nanoparticulate using scanning electron microscopy at a 700x magnification. The measurement bar $=10 \mu \mathrm{m}$. (C) Milled RMR nanoparticulate using scanning electron microscopy at a 10000× magnification. The measurement bar $=1 \mu \mathrm{m}$.

(A)

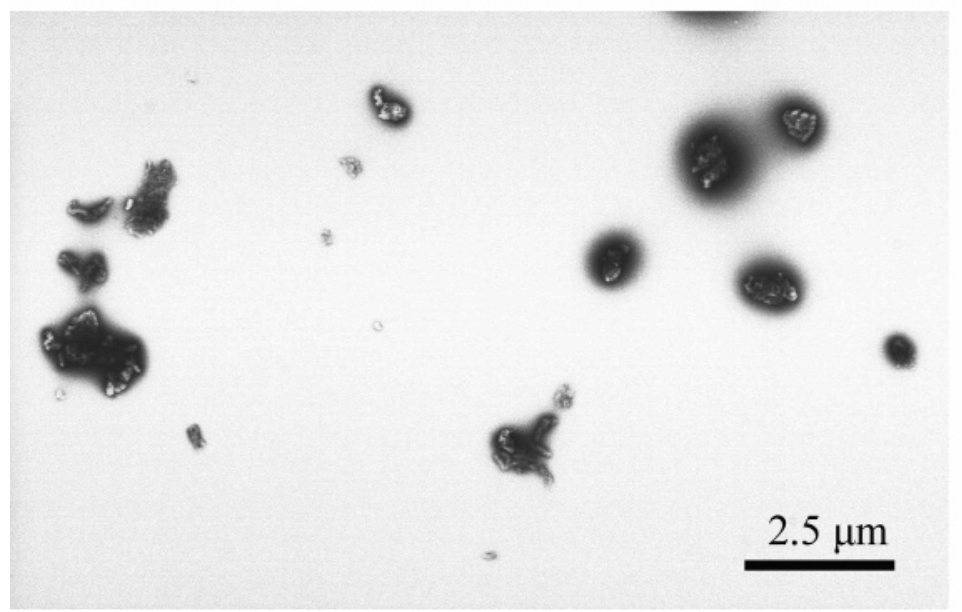

(B)

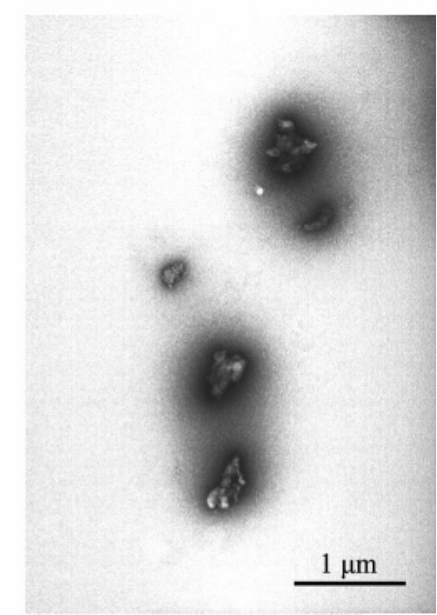

Figure 3. Transmission electron micrographs of (A) NRMR at a 4000x magnification. The measurement bar $=2.5 \mu \mathrm{m}$. (B) NRMR at a 10000x magnification. The measurement bar $=1 \mu \mathrm{m}$.

It is interesting to note that the impaction and the shearing forces generated during milling were necessary to achieve the desired results. Moreover, the size and concentration of the grinding media were important. As shown in Figure 5, mixing the RMR solution with a different size of milling media in the wet-milling process can cause different results. The results were based on the size report of dynamic laser scattering measurement, and the average size of nanoparticualtes can be calculated by these scattered intensity fluctuations on the time scale. When mixed with $0.65 \mathrm{~mm}$ grinding media, particle size reduction did not generate nanopartculates; the average size was larger than $1 \mu \mathrm{m}$. In the other milling processes, the average size of $75 \%$ RMR particle, milled with $0.2 \mathrm{~mm}$ grinding media, was about $521 \mathrm{~nm}$ and is not under ideal homogeneous conditions because $25 \%$ of the product's particle size was larger than 1 $\mu \mathrm{m}$. The last milling process utilized a two-step process, which 
(A)
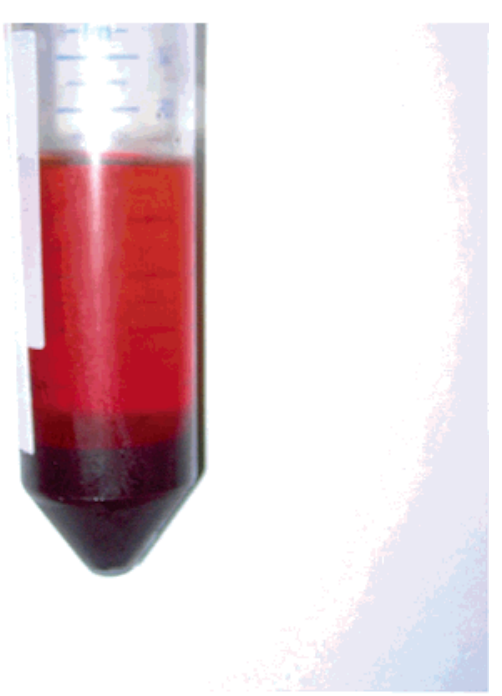

\section{(B)}

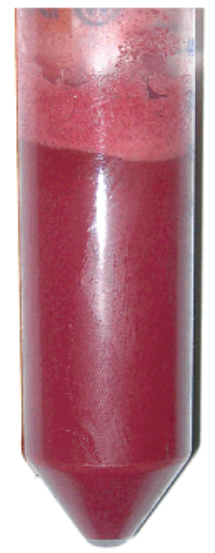

Figure 4. Graphs compare (A) unmilled RMR and (B) milled RMR stored at $4{ }^{\circ} \mathrm{C}$ for 1 week.

yielded a very homogeneous particle preparation with a mean particle size $<410 \mathrm{~nm}$. In addition, two kinds of stabilizer systems were selected. They are as follows: different concentration of pluronic F68 in combination with sodium deoxycholate and gum Arabic that has been widely used in food additives, such as chewing gum.

As shown in Table 1, despite using the $0.5 \%$ F68 with $0.05 \%$ sodium deoxycholate, the particles aggregated to about $1 \mu \mathrm{m}$; in addition, the other stablizers had similar nanoparticulate formulations and particle sizes ranging from 344.9 to $493.8 \mathrm{~nm}$. However, when stored in a refrigerator at $4{ }^{\circ} \mathrm{C}$ for 2 months, agglomeration can obviously be found in stabilizers like $5 \%$ Arabic gums no. 408 and $0.1 \%$ F68 with $0.01 \%$ sodium deoxycholate. The particle sizes increased nearly 2-fold from 2 months ago. Much in contrast to the other stabilizers, RMR powder milled with distilled water had only partial agglomeration after 2 months. As demonstrated in Figure 6, the mean particle size of this preparation increased slightly during storage from an initial mean particle size of $410-480 \mathrm{~nm}$ because partial agglomeration was observed in the RMR dispersion when stored in refrigeration after 2 months.

The secondary metabolite concentrations of the unprocessed and processed RMR particle were studied using HPLC as shown in Figures 7 and 8. Comparison between unprocessed and processed RMR particles shows that these two kinds of

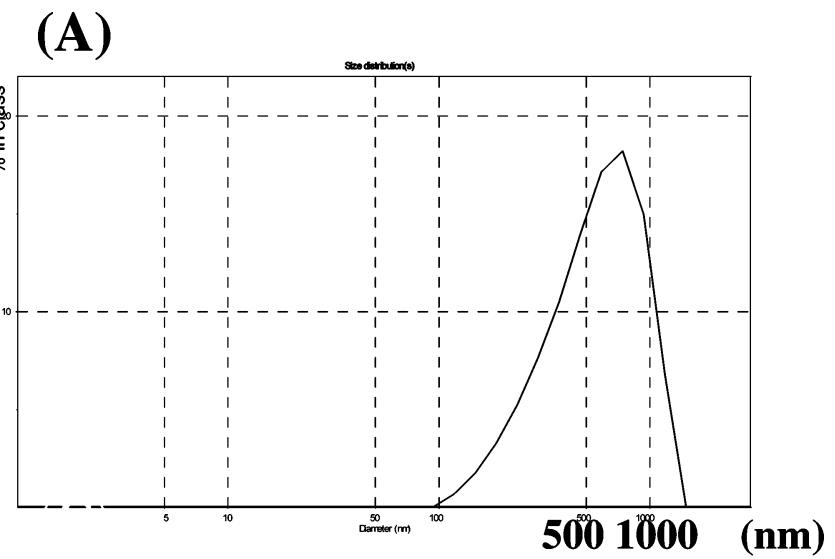

(B)

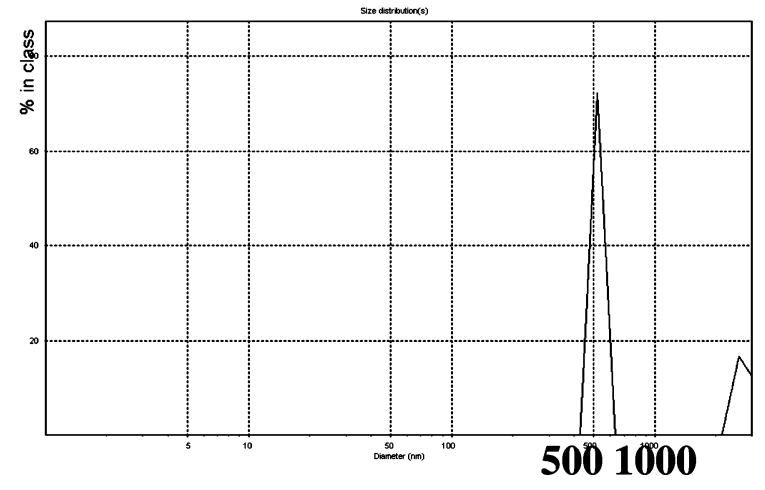

Diameter (nm)

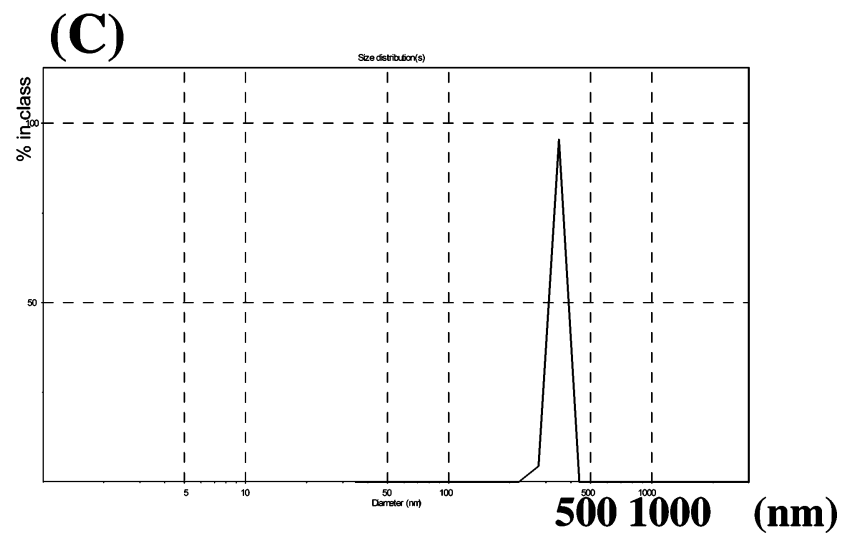

Figure 5. Effect of different grinding media size on the particle size distribution of NRMR. (A) Processed by $0.65 \mathrm{~mm}$ grinding media for $3 \mathrm{~h}$; (B) processed by $0.2 \mathrm{~mm}$ grinding media for $3 \mathrm{~h}$; and (C) two-step milling process processed by $0.65 \mathrm{~mm}$ grinding media for $1 \mathrm{~h}$ and then $0.2 \mathrm{~mm}$ grinding media for $3 \mathrm{~h}$.

secondary metabolites have different reduction rates. The HPLC profiles of monacolin K, shown in Figure 7, reveal that its major peak with a retention time of 20.43 min was identified in this study. The extraction of monacolin K was reduced from 3942 $\mathrm{mg} / \mathrm{kg}$ of unprocessed RMR to $3136 \mathrm{mg} / \mathrm{kg}$ of processed RMR, which is about a $20 \%$ reduction.

In Figure 8, the HPLC profiles of citrinin show that its major peak with a retention time of $6.66 \mathrm{~min}$ was identified. The extraction of monacolin $\mathrm{K}$ was reduced from 3815 to $1834 \mu \mathrm{g} /$ $\mathrm{kg}(52 \%$ reduction). There is evidence that the milling process affects the chemical integrity of the secondary metabolites and generates different reduction rates. Furthermore, with the 
Table 1. Comparison between Dispersive Agents with Average Particle Size and Dispersive Agents with HPLC Analysis ${ }^{a}$

\begin{tabular}{|c|c|c|c|c|}
\hline \multirow[b]{2}{*}{ dispersive agents } & \multicolumn{2}{|c|}{$\begin{array}{l}\text { average particle } \\
\text { size }(\mathrm{nm})\end{array}$} & \multicolumn{2}{|c|}{$\begin{array}{l}\text { HPLC } \\
\text { analysis }\end{array}$} \\
\hline & $\begin{array}{l}\text { after milling } \\
\text { process }\end{array}$ & $\begin{array}{l}\text { after } 2 \\
\text { months }\end{array}$ & $\mathrm{MK}^{b}(\%)$ & $\mathrm{CT}^{\mathrm{c}}(\%)$ \\
\hline distilled water & 410.2 & 480.2 & $80 \pm 4.5$ & $48 \pm 4.5$ \\
\hline arabic gums TCML 5\% & 407.8 & 496.3 & $50 \pm 2.5$ & $56 \pm 4.7$ \\
\hline arabic gums no. 408 5\% & 344.9 & 628.7 & $71 \pm 3.5$ & $48 \pm 5.5$ \\
\hline $\begin{array}{l}0.1 \% \text { F } 68 / 0.01 \% \text { sodium } \\
\text { deoxycholate }\end{array}$ & 493.8 & 673.2 & $74 \pm 1.6$ & $53 \pm 8.3$ \\
\hline $\begin{array}{l}0.5 \% \mathrm{~F} 68 / 0.05 \% \text { sodium } \\
\text { deoxycholate }\end{array}$ & 944.2 & 986.4 & $92 \pm 2.7$ & $74 \pm 5.5$ \\
\hline
\end{tabular}

${ }^{a}$ The values represent the mean $\pm \mathrm{SD}(n=3) .{ }^{b} \mathrm{MK}(\%)=$ NRMR monacolin $\mathrm{K}$ concentration/RMR monacolin $\mathrm{K}$ concentration. ${ }^{\mathrm{C}} \mathrm{CT}(\%)=\mathrm{NRMR}$ citrinin concentration/RMR citrinin concentration.

\section{(A)}

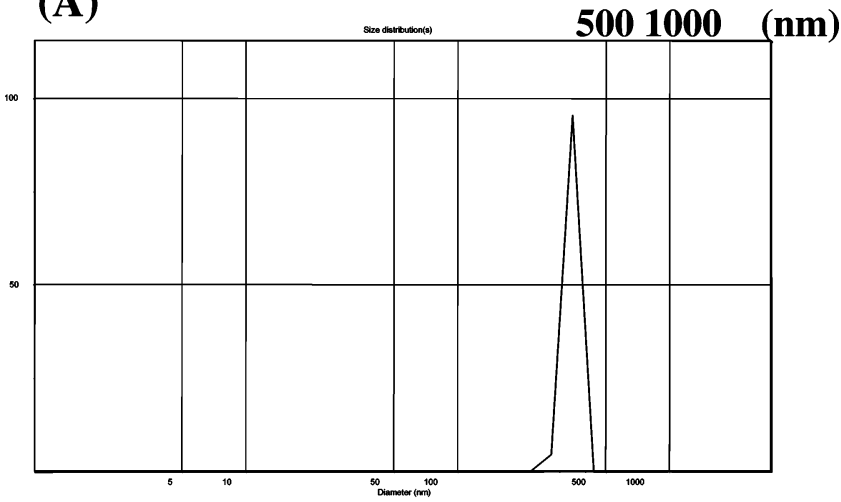

(B)

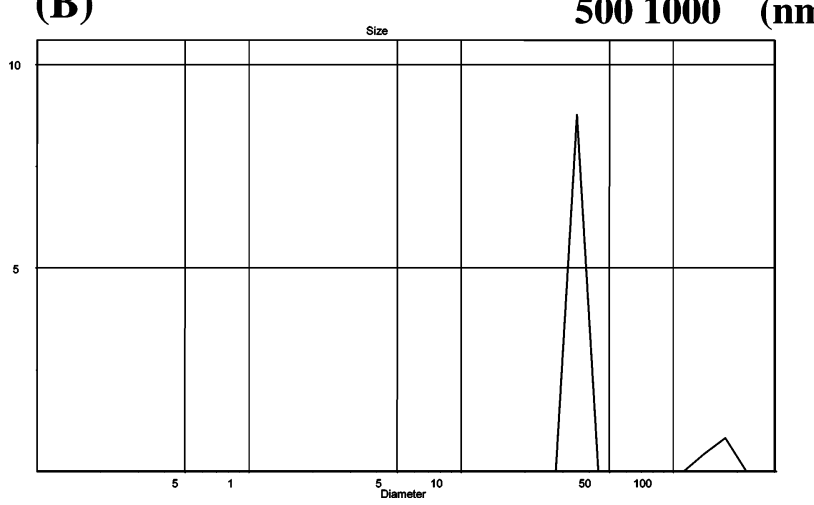

Figure 6. Particle size distribution profiles of nanopaticulate red mold rice using laser light diffraction: (A) measured immediately after milling $(410 \mathrm{~nm})$ and $(B)$ measured after storage for 2 months $(496.3 \mathrm{~nm})$.

combination of other dispersive agents added to the secondary metabolite, $0.5 \%$ F68 with $0.05 \%$ sodium deoxycholate has the highest extraction rate of monacolin $\mathrm{K}$ but $5 \%$ Arabic gums no. 408 and distilled water have the lowest extraction rate of the mycotoxin citrinin.

When testing for the levels of $\mathrm{pH}$, three different kinds of processed RMR sample had increased from $\mathrm{pH}$ levels of 4.58 to $6.4,4.82$ to 6.2 , and 4.47 to 5.56 ; also, pigment analysis showed that yellow and red pigments were reduced to 36 and $39 \%$ of their base levels after the wet-milling process. In the RMR fermentation period, Monascus can produce organic acid $(19,22,23)$ that makes the RMR more acidic; however, under a wet-milling process, the neutralization of NRMR dispersion may be due to the breakage of the cell wall. In food composition

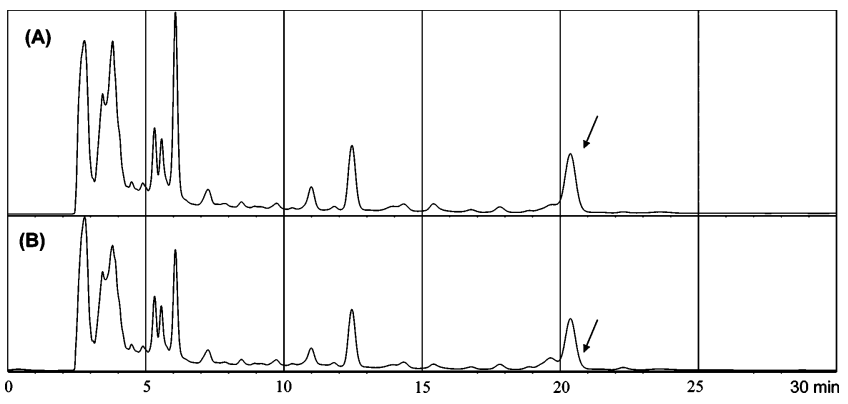

Figure 7. HPLC profile of monacolin $\mathrm{K}$ before $(\mathbf{A})$ and after $(\mathbf{B})$ the milling process at $4{ }^{\circ} \mathrm{C}$ for $4 \mathrm{~h}$. The milling process brings about a significant change in the percent of sample having retention times of $20.43 \mathrm{~min}$ $(100 \%$ in $\mathbf{A}$ to $80 \%$ in $\mathbf{B})$.

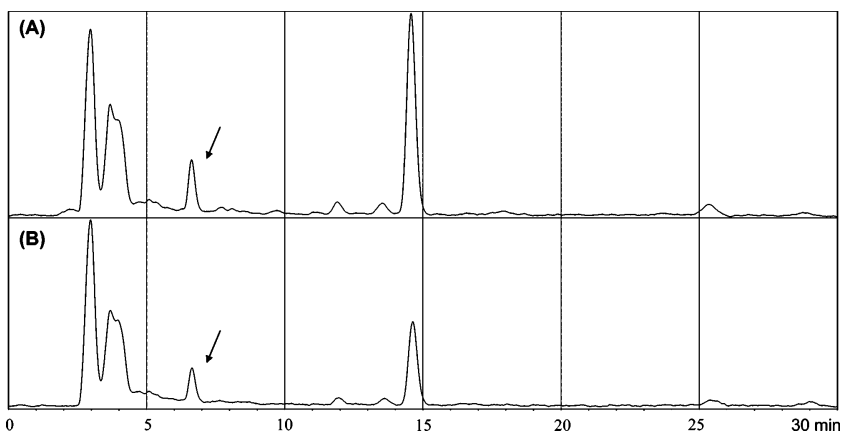

Figure 8. HPLC profile of citrinin extration before $(\mathbf{A})$ and after $(\mathbf{B})$ milling process at $4{ }^{\circ} \mathrm{C}$ for $4 \mathrm{~h}$. The milling process brings about a significant change in the percent of sample having retention times of $6.66 \mathrm{~min}(100 \%$ in $\mathbf{A}$ to $48 \%$ in $\mathbf{B})$.

Table 2. Food Composition of RMR

\begin{tabular}{lc}
\hline \multicolumn{1}{c}{ components } & content $(\mathrm{g} / 100 \mathrm{~g})$ \\
\hline moisture & \\
crude ash & 8.1 \\
crude fat & 0.78 \\
crude protein & 2.16 \\
crude carbohydrate & 8.42 \\
\end{tabular}

\footnotetext{
${ }^{a}$ Moisture was presented based on fresh RMR weight; others were presented on dry weight.
}

analysis, RMR was composed of $80.54 \%$ carbohydrate, $8.42 \%$ protein, $2.16 \%$ fat, $8.1 \%$ moisture, and $0.78 \%$ ash (Table 2).

\section{DISCUSSION}

In this study, we use wet-milling technology to grind RMR powder into a NRMR dispersion. This method has been applied successfully over the last few years $(13,24)$. In drug therapy applications, many drugs like danazol, naproxen, etoposide, piposulfan, camptothecin, paclitaxel, and $\mathrm{Zn}$-insulin are made into nanoparticulate dispersions (25-27). In fact, oral administration of drugs in the form of drug nanoparticles has been reported to have a full range of positive effects such as improving bioavailability, improving dose proportionality, reducing target organs irritation, reducing fed/fasted variability, and enhancing the absorption rate (28). RMR has been used for dietary supplements for its effects in lowering cholesterol levels. However, there are few studies focused on the discussion of the nanopaticulate process and its effects on healthy foods. RMR was chosen for this study for a number of reasons. In RMR production, citrinin (mycotoxin) that is produced from the fermentation process may have toxic effects on the human body at high concentrations (9). 
In addition, RMR is a kind of fermented rice, consisting of rice starch and intact Monascus cells. Monascus species belong to the group of ascomycetes with strong protective cell walls composed of chitin, $\beta$-glucan, and glycoprotein. Chitin, a homopolymer of $\mathrm{N}$-acetyl-D-glucosamine (Glc-NAc) residues linked by $\beta-1-4$ bonds, is a kind of indigestible fiber in the intestine (29). Moreover, in our previous study, Monascus species can live in the acidic environment (30). The cell wall structure of Monascus is very durable and not easily broken down. Therefore, it is difficult for the matter inside to be released, much less absorbed, into the human body. In some patents, methods for producing sporoderm-broken Ganoderma lucidum spores claim to have medicinal effects on patients with immunological disorders, cancer, AIDS, hepatitis, diabetes, and cardiovascular diseases $(31,32)$. Furthermore, the absorption rate of NRMR particles increases because the specific area increases after size reduction. In order to overcome these problems, milled technology, described above, is used for drug formulations to produce NRMR and to examine the effects and influences due to the wet-milling process. As shown in Figures 1-4, RMR powder was readily processed into a physically stable, nanoparticulate dispersion. As compared with the unmilling RMR particle size $(20.15 \mu \mathrm{m})$, the NRMR particle size was reduced to $410 \mathrm{~nm}$. If the particles are near spherical in shape, nanoparticles are further reduced in size from $20 \mu \mathrm{m}$ to $400 \mathrm{~nm}$ and, thus, generate a 50-fold increase in the surface area to volume ratio. This increase in surface area can have a major impact on its absorption. Improving the dissolution rate of a poorly water-soluble compound generally correlates with faster absorption rates (25). Freeze-dried NRMR extraction at $37^{\circ} \mathrm{C}$ for few seconds has nearly the same extraction efficiency in the secondary metabolite monacolin $\mathrm{K}$ as extraction at 65 ${ }^{\circ} \mathrm{C}$ for $1.5 \mathrm{~h}$ (data not shown). This suggests that an increase in the surface area to volume ratio increases the extraction efficiency at human body temperature.

A high-energy milling process will create a large amount of heat that may affect the monacolin $\mathrm{K}$ structure whose melting point is at $174.5^{\circ} \mathrm{C}(33)$. In the milling process, the temperature condition is under control at $4{ }^{\circ} \mathrm{C}$ and the aqueous phase effectively dissipates the heat generated during processing. Under controlled temperatures, there are many factors that influence NRMR particle size like milling time, grinding media particle size, the composition of grinding media, and stabilizer. In regards to milling time, the time required to obtain drug nanocrystalline dispersions with unimodal distribution profiles and mean diameters $<200 \mathrm{~nm}$ is $30-60 \mathrm{~min}$ in batch mode mill (13). However, in a noncrystalline drug such as peptide drug $\mathrm{Zn}$-insulin, the milling time required to obtain the same mean diameters of $<200 \mathrm{~nm}$ is more than $4 \mathrm{~h}$ (15). As shown in Figure 1, the graph indicates that within $1 \mathrm{~h}$ of processing, the mean particle size of the powder has reduced from $20 \mu \mathrm{m}$ to the nanometer size range, but after $3 \mathrm{~h}$, there is no more significant change observed in the particle size. This may be due to the size limitation of the grinding media. With a reduction in the size of grinding media in a media mill, the number of contact points is increased exponentially resulting in improved grinding and dispersing action. In Figure 5, the smaller the grinding media is, the smaller the NRMR particle size is. For smaller grinding media, the increase of the contact probability and impact force may cause the media sphere to fracture to pieces. To overcome this problem, we use yttria-stabilized tetragonal zirconia polycrystals (Y-TZP) as the grinding media. Among various kinds of grinding media, Y-TZP offers a combination of properties (high hardness, fracture toughness, spherical shape, and chemical stability), which make them very suitable for this study (34).

The stabilizer selections are used to promote the particle size reduction process, generate physically stable formulations, and prevent the high surface energy of nanometer-sized particles from agglomerating or aggregating. Too little stabilizer induces agglomeration or aggregation and too much stabilizer promotes Ostwald ripening (13). In this study, we select two kinds of stabilizer systems: pluronic F68 in combination with sodium deoxycholate and gum Arabic. Pluronic F68 is a block copolymer of ethylene oxide (hydrophilic) and propylene oxide (hydrophobic). When F68 is mixed with sodium deoxycholate (cosurfactant), the mixture is widely used in modifying drug nanoparticle surfaces to avoid agglomeration or aggregation after high-energy wet milling. Gum arabic (gum acacia), a kind of food additive, is composed of protein and high molecular weight polysaccharides that can be used as a thickener, stabilizer, and dispersion media (11). Unfortunately, these have problems such as aggregation and coagulation (Table 1). Surprisingly, as compared with other stabilizers, NRMR powder milled with distilled water has a similar particle size distribution $(410 \mathrm{~nm})$ and only partial agglomeration after 2 months (Figure 6). In HPLC analyses, its monacolin K extraction level was the second highest, maintained at $80 \%$ of its base level, while citrinin only constituted $48 \%$ extraction (the lowest). Moreover, as shown in food composition analysis (Table 2), RMR is a mixture of carbohydrate, protein, and fat that is entirely different from crystalline drugs. The data may imply that RMR powder itself may be used as a kind of stabilizer. The above data suggest that mixing RMR with distilled water to formulate NRMR dispersion provided an economical, simple, and physically stable product that can be used for further biological and food industrial uses.

It is concluded that the wet-milling technology can be used to formulate physically stable NRMR dispersions along with higher monacolin $\mathrm{K}$ extractions and lower citrinin extractions. This technology can be applied not only to poorly water-soluble drugs but also to functional foods. Further studies are being conducted to demonstrate the biological effect and safety evaluation of NRMR and to utilize this approach for other functional foods.

\section{LITERATURE CITED}

(1) Su, Y. C.; Chen, W. L.; Lee, Y. H. Studies on the Anka Pigment Product by a Mutant of Monascus Anka Memorial Collect of Agriculture; National Taiwan University: Taipei, 1973; Vol. 14, pp 41-56 (in Chinese).

(2) Tsuji, K.; Ichikawa, T.; Tanabe, N.; Obata, H.; Abe, S.; Tarui, S.; Nakagawa, Y. Extraction of hypotensive substance from weat beni-koji. Nippon Shokuhin Kogyo Gakkaish 1992, 39, 913918.

(3) Budavari, S.; Maryadele, J. O.; Smith, A.; Heckelman, P. E. The Merck Index; Merck \& Co.: Rahway, NJ, 1989; Vol. 11, pp 2330-2331.

(4) Endo, A. Monacolin K, a new hypocholesterolemic agent that specifically inhibits 3-hydroxy-methylglutaryl coenzyme A reductase. J. Antibiot. 1980, 23, 334-337.

(5) Su, Y. C.; Wang, J. J.; Lin, T. T.; Pan, T. M. Production of the secondary metabolites $\gamma$-aminobutyric acid and monacolin $\mathrm{K}$ by Monascus. J. Ind. Microbiol. Biotechnol. 2003, 30, 41-46.

(6) Kohama, Y.; Matsumoto, S.; Mimura, T.; Tanabe, N.; Inada, A.; Nakanishi, T. Isolation and identification of hypotensive principles in red-mold rice. Chem. Pharm. Bull. 1987, 35, 24842489. 
(7) Kushiro, T.; Hashida, J.; Kawamura, H.; Mitsubayashi, H.; Saito, T.; Suzuki, Y.; Takahashi, N.; Ishii, T.; Kimura, T.; Tsuji, K.; Tanabe, N.; Asano, K.; Abe, S.; Tarui, S. Clinical effects of benikoji in mild essential hypertension-A multi-center double-blind comparison with placebo. Nippon Jinzo Gakkai Shi 1996, 38, $625-633$.

(8) Aniya, Y.; Yokomakura, T.; Tonamine, M.; Shimada, K.; Nagamine, T.; Shimabukura, M.; Gibo, H. Screening of antioxidant action of various molds and protection of Monascus anka against experimentally induced liver injuries of rats. Gen. Pharmacol. 1999, 32, 225-231.

(9) Blanc, P. J.; Loret, M. O.; Goma, G. Production of citrinin by various species of Monascus. Biotechnol. Lett. 1995, 17, 291294.

(10) Heber, D.; Yip, I.; Ashley, J. M.; Elashoff, D. A.; Elashoff, R. M.; Go, V. L. W. Cholesterol-lowering effects of a proprietary Chinese red-yeast-rice dietary supplement. Am. J. Clin. Nutr. 1999, 69, 231-236.

(11) Liversidge, G. G.; Cundy, K. C.; Bishop, J. F.; Czekai, D. A. Surface modified drug nanoparticles. U.S. Patent 5,145,684, 1992.

(12) Yokoyama, T.; Huang, C. C. Nanoparticle technology for the production of functional materials. "KONA" Powder Sci. Technol. Jpn. 2005, 23, 7-16.

(13) Merisko-Liversidge, E.; Liversidge, G. G.; Cooper, E. R. Nanosizing: A formulation approach for poorly water soluble compounds. Eur. J. Pharm. Sci. 2003, 18, 113-120.

(14) Muller, R. H.; Jacobs, C.; Kayser, O. Nanosuspensions as particulate drug formulations in therapy: Rationale for development and what we can expect for the future. Adv. Drug Delivery Rev. 2001, 47, 3-19.

(15) Merisko-Liversidge, E.; McGurk, S. L.; Liversidge, G. G. Insulin nanoparticles: A novel formulation approach for poorly water soluble Zn-insulin. Pharm. Res. 2004, 21, 1545-1553.

(16) Pecora, R. Dynamic light scattering measurement of nanometer particles in liquids. J. Nanopart. Res. 2000, 2, 123-131.

(17) Liu, B. H.; Wu, T. S.; Su, M. C.; Chung, C. P.; Yu, F. Y. Evaluation of citrinin occurrence and cytotoxicity in Monascus fermentation products. J. Agric. Food Chem. 2005, 53, 170175.

(18) Lee, C. L.; Wang, J. J.; Pan, T. M. A synchronous analysis method for detection of citrinin and the lactone and the acid form of monacolin $\mathrm{K}$ in red mold rice. J. AOAC Int. 2006, 89, 669-677.

(19) Hajjaj, H.; Blanc, P.; Groussac, E.; Uribelarrea, J.; Goma, G.; Loubiere, P. Kinetic analysis of red pigment and citrinin production by Monascus ruber as a function of organic acid accumulation. Enzyme Microb. Technol. 2000, 27, 619-625.
(20) Lin, C. F.; Iizuka, H. Production of extracellular pigment by mutant of Monascus kaoliang sp. nov. Appl. Environ. Microbiol. 1982, 43, 671-676.

(21) AOAC. Official Methods of Analysis, 14th ed.; Association of Official Analytical Chemists: Washington, DC, 1984.

(22) Tseng, Y. Y.; Chen, M. T.; Lin, C. F. Growth, pigment production and protease activity of Monascus purpureus as affected by salt, sodium nitrite, polyphosphate and various sugars. J. Appl. Microbiol. 2000, 88, 31-37.

(23) Lin, C. W; Chou, W. L. Strain screening of Monascus sp. on oriental type cheese manufacturing and its mycological profile. J. Chin. Anim. Sci. 1998, 27, 143-162.

(24) Radtke, M. Pure drug nanoparticles for the formulation of poorly soluble drugs. J. New Drugs 2001, 3, 62-68.

(25) Liversidge, G. G.; Cundy, K. C. Particle size reduction for improvement of oral bioavailability of hydrophobic drugs: I. Absolute oral bioavailability of nanocrystalline danazol in beagle dogs. Int. J. Pharm. 1995, 125, 91-97.

(26) Liversidge, G. G.; Conzentino, P. Drug particle size reduction for decreasing gastric irritancy and enhancing absorption of naproxen in rates. Int. J. Pharm. 1995, 125, 309-313.

(27) Merisko-Liversidge, E.; Sarpotdar, P.; Bruno, J.; Hajj, S.; Wei, L.; Peltier, N.; Rake, J.; Shaw, J. M.; Pugh, S.; Polin, L.; Jones, J.; Corbett, T.; Cooper, E.; Liversidge, G. G. Formulation and antitumor activity evaluation of nanocrystalline suspensions of poorly soluble anticancer drugs. Pharm. Res. 1996, 13, 272278.

(28) Liversidge, G. G. Drug nanocrystals for improved drug delivery. Int. Symp. Control. Release Bioact. Mater. Workshop on particulate drug delivery systems, 1996; Vol. 23.

(29) Gurr, M. I.; Asp, N. G. Dietary Fibre, 2nd ed.; ILSI Press: Washington, DC, 1994.

(30) Lee, C. L.; Wang, J. J.; Pan, T. M. Increasing monacolin K production of Monascus spp. under low $\mathrm{pH}$ value condition. Proc. Gen. Meeting Am. Soc. Microbiol. 2005, 433.

(31) Liu, X.; Chung, C. K. Germination activated Ganoderma lucidum spores and method for producing the same. U.S. Patent 6,468,542, 2002.

(32) Chung, C. K.; Tong, S. K. Ganoderma lucidum spores for treatment of autoimmune diseases. U.S. Patent 6,893,641, 2005

(33) Monaghan, R. L.; Alberts, A. W.; Hoffman, C. H.; AlbersSchonberg, G. Hypocholesteremic fermentation products and process of preparation. U.S. Patent 4,231,938, 1980.

(34) Farber, B. Y.; Graves, G. A. Ceramic Media with improved efficiency. PCI 2001, Apr, 30-41.

Received for review April 2, 2006. Revised manuscript received June 24, 2006. Accepted June 30, 2006.

JF0609274 